\title{
Apresentação - Resistir
}

Organizado pelos grupos de pesquisa Narrativas de Resistência (NARRARES) e Estéticas, Performances e Hibridismos (ESPERHI), o III Seminário Nacional Literatura e Cinema de Resistência (SELCIR), realizado na Universidade Federal do Pará (UFPA), vem ao longo dos últimos anos se consolidando como um espaço fundamental para debater diversos aspectos que norteiam as pesquisas sobre resistência política e suas implicações nas artes, em especial na literatura e no cinema.

Em sua terceira versão, a memória foi a categoria escolhida para nortear as discussões sobre resistência, e desse modo muitos dos estudos apresentados no decorrer do evento debateram mecanismos de seleção, lembrança, encobrimento, recriação, olvido e reparação, entre tantos outros observados nos vários objetos analisados: filmes de ficção, documentários, curtas-metragens, romances, contos, crônicas, narrativas orais, depoimentos, testemunhos, poemas, canções e peças teatrais, que foram alvos das mais diversas práticas críticas, abrangendo uma grande diversidade de enfoques.

Entre as atividades integradas ao evento destacamos a realização da III Mostra Latino -Americana de Cinema de Resistência, que proporcionou a projeção dos seguintes títulos: Garage Olimpo, Quase dois irmãos, Valentin, $O$ ano em que meus pais saíram de férias, Tony Manero, Araguaia: campo sagrado, Kamchatka, Linha de passe, Machuca, Cidadão Boilesen, Perdita Durango, Boleiros - Era uma vez o futebol..., Em teu nome, Batismo de sangue, Que bom te ver viva, No olho do furacão. A Mostra se pautou na diversidade das formas cinematográficas, bem como procurou apontar para a possibilidade de nelas compreender a resistência e suas derivações, como temas nucleares, sem perder de vista a inserção destas formas nos regimes estéticos da contemporaneidade.

A projeção dos filmes se fez acompanhar da apresentação de textos analíticos produzido por vários pesquisadores, que estiveram envolvidos na construção do evento e da Mostra, tarefa que objetivou provocar o debate com o público. Tais análises, uma vez convertidas para a forma de artigo, resultaram na construção de potenciais elucidações acerca de aspectos que convergem para a constituição da resistência nas produções citadas, ora detendo-se em um olhar sobre os filmes, ora procurando amealhar em outras produções não fílmicas a possibilidade de estabelecer diálogos aproximativos. A reunião desse material ora compõe o dossiê Literatura e Cinema de Resistência, da Revista Literatura e Autoritarismo.

Em todos os estudos integrados ao dossiê, a resistência foi pensada como categoria catalisadora e mediadora da reflexão acerca da memória, no interior dos regimes de exceção e, do mesmo modo, naquilo que chamamos de situações de exceção, como é possível observar nos filmes Perdita Durango e Linha de passe, em que as situações catastróficas não são exatamente produzidas por um cenário em que prevalece a ausência do estado de direito, mas a instauração do ilícito e suas repercussões, que terminam por se constituir em convite ao 
pensar acerca das possibilidades de resistência e suas representações.

Estas representações por sua vez perpassam por várias possibilidades de leitura no campo especulativo, pois como diria Federico Lorenz em um ensaio chamado Resistências, que integra o livro Memória e resistência, a resistência não se esgota nos enfrentamentos armados ou nas guerras, ainda que grande parte das representações a ela ligadas se façam relacionadas às imagens bélicas. É nesse anteparo que concernem os antagonismos, as lutas, os enfrentamentos, as provocações e desafios que marcam todo ethos resistente.

Diz Lorenz: "Se são vitoriosas, as resistências aparecem em relatos nacionais fundadores, constituintes ou que pretendem construir uma identidade" ${ }^{1}$, porém, "outras vezes, a resistência culmina em derrota, e sem dúvida este é o componente central das formas que as imaginamos hoje como conceito, objeto e problema" ${ }^{2}$. Este componente central de que nos fala Lorenz, de fato se faz presente desde as conjecturas de Alfredo Bosi, em Literatura e resistência, que propõe a resistência como elemento estruturante da narrativa e da poesia, até os estudos que convergem para as variáveis da narrativa e da poesia de resistência, como o de Bárbara Harlow, intitulado Literatura de resistência.

Para Harlow a concepção de resistência se fundamenta nas posturas e nos discursos constituídos contra formas de domesticação e silenciamento, acreditando que toda arte de resistência deve estar necessariamente fundada no compromisso em "recobrar a historicidade expropriada" (Harlow, 1993, p. 66).

Ao analisar mais especificamente a poesia e a narrativa de resistência, a matéria que Harlow privilegia é, por exemplo, aquela dos poemas do poeta Pablo Neruda ao falar do assassinato de outro poeta, o nicaraguano Augusto Sandino, crime que se dá no contexto do violento governo de Somoza, apoiado pelos Estados Unidos. Ou ainda o romance intitulado Um passeio no torvelinho, de Sipho Sempala, que retrata vários problemas no âmbito dos acontecimentos ligados ao aparthaid ocorrido na África do Sul. As categorizações construídas por Harlow se afinam ao pensamento de Edward Said. Por esses parâmetros a narrativa de resistência surgiria das reelaborações acerca das certezas universalizantes, próprias dos discursos colonizadores, especialmente marcados pela aura racionalista Ocidental. Trata-se de uma narrativa de resistência que se coloca como discurso paralelo e confrontador, capaz de reinterpretar o passado, as identidades e construir uma nova visão da história, que se interpõe como processo e esforço descolonizador.

Sem dúvida, os dois exemplos que extraímos das análises propostas por Barbara Harlow tratam de uma poesia e uma narrativa da resistência porque falam muito de perto sobre a necessidade de manter-se viva a historicidade desses acontecimentos, a partir da perspectiva do oprimido, do perseguido, da minoria etc., mostrando aí situações vexatórias que ferem a dignidade humana, e que quase sempre resvalam para o padecimento desses sujeitos, em função das atrocidades físicas e psíquicas, cometidas tanto em âmbito individual quanto coletivo: prisões e exílios, práticas de tortura, extermínios, privações, etc.

\footnotetext{
${ }^{1}$ No original: "Si son victoriosas, las resistencias aparecen em relatos nacionales fundacionales, constituyentes o que pretenden construir una indentidad".

2 "otras veces, la resistencia culmina en derrota, y sin duda ese es um componente central de las formas en las que las imaginamos hoy como concepto, objeto y problema”.
} 
Nesse sentido, são narrativas da resistência porque nos dão notícias dessas práticas atrozes a partir de matérias historiográficas específicas. As expressões narrativa da resistência e poesia da resistência, pela condição transitiva que as constituem, solicitam assim uma identificação objetiva com tais matérias historiográficas, com as quais se encontram tematicamente comprometidas.

Contudo, para além dessas matérias historiográficas específicas, fortemente datadas, acreditamos que os fundamentos-chaves da resistência, aquilo que chamaríamos de núcleos de uma razão resistente, residem na divergência, no antagonismo e no deslocamento. Não há resistência sem o divergente. Não há divergentes sem antagonismos. Também não há resistência sem que ocorra um deslocamento visível em relação às situações consideradas "oficiais" ou mesmo em relação àquelas práticas que estão fixadas no interior de universo cultural, e cuja suposta normalidade não nos permitem perceber o desvirtuamento que fazem em relação a determinados valores importantes para a condição humana. Visto desse modo, avaliamos que ao refletir sobre a condição humana, sem necessariamente envolver uma matéria histórica datada, a poesia e a narrativa seriam, sobretudo, de resistência, e não mais somente da resistência.

Tais compreensões certamente norteiam a coletânea de artigos presentes neste dossiê.

No trabalho Sobre os filmes Em teu nome, de Paulo Nascimento, e Batismo de sangue, de Helvécio Ratton, Augusto Pachêco desenvolve uma análise a respeito da prática da tortura, durante a ditadura militar no Brasil, nos anos 70, a partir das narrativas citadas no título. Além disso, ele procura realizar uma cartografia do drama político e histórico como um dos gêneros explorados pelo cinema brasileiro das últimas décadas.

A sobrevivência no olho do furacão, artigo de Augusto Sarmento-Pantoja e Adriana Cruz dos Santos, trata da performance do testemunho em dois documentários: o primeiro de 1989, Que bom te ver viva, de Lúcia Murat, e o segundo de 2003, No olho do furacão, de Renato Tapajós e Tony Venturi.

Em Coreografias do poder, Alberto Amaral e Lilian Lobato discutem as formas de resistência presentes nos filmes de ficção Quase Dois Irmãos, de Lucia Murat, Valentin, de Alejandro Agresti, e no curta-metragem Baseado em estórias reais, de Gustavo Moraes. Inspirada em Foucault, a análise move-se a partir dos conflitos originados no choque entre as relações de poder, no interior de um estado de exceção, ou mesmo em âmbito familiar.

No artigo Batismo de sangue: resistência da palavra contra a ditadura no Brasil, os autores Breno Velasco, Edvaldo Pereira e Regina Costa pretendem fazer uma análise dos aspectos sociopolíticos abordados na adaptação fílmica Batismo de Sangue, utilizando outras narrativas ficcionais para elucidar a ideia de narrativa verídica. Eles também traçam discussões a respeito do conteúdo proposto pelo cinema de resistência no Brasil, focalizando o período ditatorial, contexto no qual as personagens do livro-testemunho e do filme-arquivo relatam os acontecimentos violentos, de ameaça e tortura, impostos às vítimas que se opunham ao sistema então vigente.

Por sua vez Arte e guerra: a violência como um elo entre as narrativas fílmicas Tony Manero, Machuca e $\mathrm{O}$ ano em que meus pais saíram de férias, de Carlos Henrique Lopes de Almeida e Jessika Bastos, constitui-se em um estudo sobre as referências políticas presentes na cinematografia da América Latina, utilizando como tema central a deflagração 
dos regimes militares no Chile e no Brasil, a partir dos filmes Tony Manero, Machuca e O ano em que meus pais saíram de férias, que apresentam fortes reminiscências da história das ditaduras nesses países.

O artigo A cidadania na narrativa de resistência: um olhar sobre as narrativas audiovisuais $\mathrm{O}$ ano em que meus pais saíram de férias e Cidadão Boilense, de autoria de Lenice Andrade, Marcela Costa e Tânia Sarmento-Pantoja, objetiva desenvolver uma análise das narrativas audiovisuais citadas no título, com vistas a compor algumas reflexões acerca das diferentes configurações da ideia de cidadania, a partir do modo como tais configurações são apresentadas nos dois filmes.

O texto Memórias da violência na América Latina: Araguaia - Campo Sagrado, Kamchatka e Linha de Passe, de Deurilene Sousa e Veridiana Pinheiro, procura traçar uma reflexão envolvendo violência, trauma e memória, presentes no documentário Araguaia campo sagrado e nos filmes de ficção Kamchatka e Linha de passe. As autoras observam como as representações destas categorias podem resvalar para um pensar sobre a resistência, a partir de diferentes faces da recente cinematografia literária brasileira e argentina.

O trabalho A construção da personagem Perdita Durango como elemento estético de resistência, de Neuton Martins Filho e Suellen Batista, apresenta uma análise sobre a construção da personagem como elemento de resistência.

Finalizando o dossiê, o estudo A significação do grotesco na narrativa de testemunho de Primo Levi, de Viviane Moraes, pretende desenvolver uma análise em torno dos efeitos de grotesco na escrita de Primo Levi, partindo da hipótese de que são tais efeitos os responsáveis pela abjeção na linguagem do testemunho, como tentativa de externar e revelar um estado de alma em agonia.

Agradecemos ainda a Fundação Amazônia Paraense (FAPESPA) e à Coordenação de Aperfeiçoamento de Pessoal de Nível Superior (CAPES) que apoiaram a realização do Seminário Nacional Literatura e Cinema de Resistência e a Mostra Latino-Americana de Cinema de Resistência.

\section{Tânia Sarmento-Pantoja Elcio Loureiro Cornelsen}

